\title{
Baseline characteristics of postmenopausal women with osteoporosis treated with teriparatide in a real-world setting in Latin America: a subregional analysis from the Asia and Latin America Fracture Observational Study (ALAFOS)
}

Joao L. Cunha-Borges ${ }^{1}$, Guillermo Meléndez Mier², Noemí Casas³, Adriana Medina ${ }^{4}$, Jose Fernando Molina ${ }^{5}$, Maria Laura García ${ }^{6}$, Lindomar Guimarães Oliveria ${ }^{7}$, Marcela S. Caselato ${ }^{8}$, Angélica C. Cruz ${ }^{9}$, Vanessa Ippolito ${ }^{8}$ and Sandra Flórez ${ }^{10,11^{*}}$ (i)

\begin{abstract}
Background: Osteoporosis is a major healthcare concern in Latin America. Factors such as changing demographics, fragmented healthcare systems, and financial considerations may result in a huge increase in the burden of osteoporosis in this region. The aim of this article is to describe the baseline clinical characteristics and fracture history of patients who are prescribed teriparatide in normal clinical practice in Latin America.

Methods: We conducted a prospective, multinational, observational study (the Asia and Latin America Fracture Observational Study [ALAFOS]) in 20 countries worldwide to assess the incidence of fractures in postmenopausal women with osteoporosis receiving teriparatide as a part of routine clinical practice in a real-world setting. In this subregional analysis of the ALAFOS study, we report the clinical characteristics, fracture history, risk factors for osteoporosis, comorbidities, previous osteoporosis therapies and health-related quality of life measures at baseline for patients from the four participant Latin American countries: Argentina, Brazil, Colombia, and Mexico.

Results: The Latin America subregional cohort included 546 postmenopausal women (mean [SD] age: 71.0 [10.1] years; range: $40-94$ years), constituting 18\% of the ALAFOS total population. The baseline mean (SD) bone mineral density T-scores were $-3.02(1.23)$ at the lumbar spine and - 2.31 (0.96) at the femoral neck; $62.8 \%$ of patients had a history of low trauma fracture after the age of 40 years and $39.7 \%$ of patients had experienced $\geq 1$ fall in the past year. Osteoporosis medications were used by $70.9 \%$ of patients before initiating teriparatide. The median (Q1, Q3) EQ-5D-5 L Visual Analog Scale (VAS) scores for perceived health status at baseline was $70(50,80)$. The mean (SD) worst back pain numeric rating scale score for the overall Latin American cohort was 4.3 (3.4) at baseline.

(Continued on next page)
\end{abstract}

\footnotetext{
* Correspondence: florez_sandra@lilly.com

${ }^{10}$ Eli Lilly Interamerica, Transversal 18 No. 96-41, Piso 6, Bogotá, Colombia

${ }^{11}$ Pain and Palliative Care Unit, Universidad de la Sabana, Bogotá, Colombia

Full list of author information is available at the end of the article
}

(c) The Author(s). 2019 Open Access This article is distributed under the terms of the Creative Commons Attribution 4.0 International License (http://creativecommons.org/licenses/by/4.0/), which permits unrestricted use, distribution, and reproduction in any medium, provided you give appropriate credit to the original author(s) and the source, provide a link to the Creative Commons license, and indicate if changes were made. The Creative Commons Public Domain Dedication waiver (http://creativecommons.org/publicdomain/zero/1.0/) applies to the data made available in this article, unless otherwise stated. 


\begin{abstract}
(Continued from previous page)
Conclusions: This baseline analysis of the Latin America subregion of the ALAFOS study indicates that patients who are prescribed teriparatide in the four participant countries had severe osteoporosis and high prevalence of fractures. They also had back pain and poor health-related quality of life. The proportions of patients with severe or extreme problems on the EQ-5D-5 L individual domains were lower than those in the overall ALAFOS study population.
\end{abstract}

Keywords: Osteoporosis, Teriparatide, Latin America, Observational study, ALAFOS

\section{Background}

Osteoporosis is a systemic bone disease characterized by loss of bone mass and deterioration of bone microarchitecture and bone quality, leading to an increased risk of fragility fractures [1]. Since there are no obvious symptoms of osteoporosis, this condition is often diagnosed after the occurrence of a fragility fracture [2]. Osteoporotic fractures can lead to pain, loss of functionality, limitation of daily activities, and extensive morbidity [1]. Osteoporotic hip and vertebral fractures have a significant adverse impact on the quality of life [3]. There is also increasing awareness about the importance of osteoporotic fractures at sites other than the hip and spine, which also contribute substantially to disability and impaired quality of life [4]. Consequently, osteoporotic fractures highly burden the healthcare system in terms of increased hospitalizations, surgeries, and prolonged home care and rehabilitation requirements [1]. For example, a large study conducted in the United States over a 12-year period (2000-2011) in postmenopausal women $\geq 55$ years of age found that the hospitalization costs for osteoporotic fractures were greater than those for other serious conditions such as stroke, myocardial infarction, and breast cancer [5]. The direct and indirect annual costs of hip fracture were estimated to be USD 34.8 billion worldwide in the year 1990; worldwide costs of osteoporosis are expected to reach approximately USD 132 billion by the year $2050[1,3]$.

In the Latin America (LA) region, osteoporosis and osteoporotic fractures continue to be a major healthcare concern [1]. The Latin American Vertebral Osteoporosis Study (LAVOS) conducted in five countries across LA in women $\geq 50$ years old found that the standardized prevalence of radiographic vertebral fractures was 11.18 (95\% confidence interval [CI] 9.23-13.4) [6]. Another population-based study found that LA accounted for 7\% of all hip fractures in the world in the year 1990, and this percentage is predicted to increase to $12.5 \%$ by the year 2050 [7]. This increase may be attributable to demographic changes such as increasing life expectancy accompanied by a corresponding increase in the elderly population in LA; the proportion of people over 50 years of age in LA is expected to increase from $\sim 13-20 \%$ of the population in 2018 to $\sim 28-40 \%$ in 2050 [1]. A recent consensus position paper reports that the increase in the elderly population in LA, along with other factors such as fragmented healthcare systems, limited resources, and financial considerations, may lead to an enormous increase in the burden of osteoporosis in this region [1].

Teriparatide is a bone-forming drug approved worldwide for the treatment of men and postmenopausal women at a high risk for fracture $[8,9]$. The Asia and Latin America Fracture Observational Study (ALAFOS) is a large, multinational, prospective, observational study being conducted in 20 countries across the world to evaluate the incidence of fractures in postmenopausal women with osteoporosis receiving teriparatide as a part of normal clinical practice and to assess factors related to treatment persistence and adherence [10]. This analysis focuses on the LA subregion of the ALAFOS study, which includes the following four countries: Argentina, Brazil, Colombia, and Mexico. We describe the baseline clinical characteristics and fracture history of patients who are prescribed teriparatide in routine clinical practice in LA. We believe that the results of the ALAFOS study will be useful to healthcare providers, payers, and health agencies to help them better understand the profile of patients who are prescribed teriparatide in the participant countries, how they compare with other countries around the globe, and provide real-world insights into factors influencing treatment persistence and response to treatment.

\section{Methods \\ Study design and participants}

The ALAFOS study population included teriparatidenaïve, postmenopausal women with osteoporosis at a high risk of fracture who were prescribed teriparatide (Forteo ${ }^{\circ}, 20 \mu \mathrm{g} /$ day) as per the clinical judgment of their treating physician and local medical care practices. The manufacturer of Forteo ${ }^{\circ}$, Eli Lilly and Company, did not provide teriparatide for this study. Patients were excluded from the study if they had any contraindications described in the teriparatide label. The treating physicians were responsible for all decisions regarding diagnosis and treatment of patients.

The detailed study design and the baseline patient characteristics of the overall ALAFOS study cohort have 
been previously published [10]. The study consists of an active treatment phase where patients receive teriparatide up to 24 months and a post-treatment, follow-up phase up to 12 months. Routine patient visits are scheduled at baseline, and at approximately 3 months, 6 months, and every 6 months thereafter (Fig. 1). Data collection is planned at the time of these routine visits. Information collected at baseline includes demographic characteristics, risk factors for osteoporosis/fractures, concomitant illnesses/medications, use of specific back pain/osteoporosis medications, past history of fragility fractures after 40 years of age, and health-related quality of life (HRQoL) scores.

The first patient visit was in September 2015 and the planned last patient visit for the study will be approximately November 2019. The study is being conducted as per the principles of Good Clinical Practice and in compliance with applicable local laws and regulations. The study has been approved by the appropriate local bodies and all eligible participants need to sign a Consent to Release Information form.

\section{Outcome measures}

The primary effectiveness variable is the occurrence of new clinical fractures (a composite of clinical vertebral and nonvertebral fragility fractures) in postmenopausal women receiving teriparatide for up to 24 months, in relation to the duration of treatment with teriparatide. The effectiveness analysis population includes all patients for whom teriparatide therapy start and end dates are available.

Secondary endpoints include evaluation of HRQoL, back pain, physical function, and factors related to medication adherence. Details regarding the scoring systems used for evaluation of these measures have been previously published [10]. Data regarding protocol-defined adverse events will also be collected (including all fractures, fracture-related hospitalizations/surgeries, any fatal outcomes, and any adverse events that result in teriparatide treatment discontinuation).

\section{Statistical analyses}

In this article, we present the baseline data for the LA subregion (a pre-specified subregion defined based on similar ethnic/racial origins, comparable health care systems, and guidelines for teriparatide use; $N=546 \mathrm{pa}-$ tients), along with the baseline data for the four countries from this subregion (Colombia $[N=277$; 50.7\%], Brazil $[N=130 ; 23.8 \%]$, Mexico $[N=83 ; 15.2 \%]$, and Argentina [ $N=56 ; 10.3 \%]$. We have used descriptive statistics to analyze the study population over time (means and standard deviations [SDs] or medians and first and third quartiles [Q1, Q3] for continuous variables; counts and percentages for categorical variables). Data analysis was performed using SAS v9.4 or higher (SAS Institute Inc., Cary, NC, USA). No statistical comparisons were performed among the four countries and the overall LA subregional group.

\section{Results}

The final baseline analysis of the overall population enrolled in the ALAFOS study across 20 countries included 3031 patients [10]. The LA subregion included 556 patients, of which 10 patients were excluded due to some key missing demographic data at the datalock time point. Thus, the final baseline analysis for the LA subregion included 546 patients, constituting $18 \%$ of the ALAFOS total population.

The baseline demographic characteristics and reproductive history of patients included in the LA subregion and the four constituent countries are described in Table 1. At baseline, the mean (SD) age in the LA subregional cohort was 71.0 (10.1) years. The mean (SD) body mass index (BMI) was $25.2(3.9) \mathrm{kg} / \mathrm{m}^{2}$ and was consistent across all four participant countries (Table 1). The mean (SD) age at onset of menopause was 47.5 (5.6) years and early menopause was reported in $7.3 \%$ of patients. Surgical menopause was reported in $20.3 \%$ of patients in the LA subregional cohort with Mexico reporting the highest rate (42.2\%; Table 1$)$.

Multinational, prospective, observational, non-interventional, outpatient, single-arm study

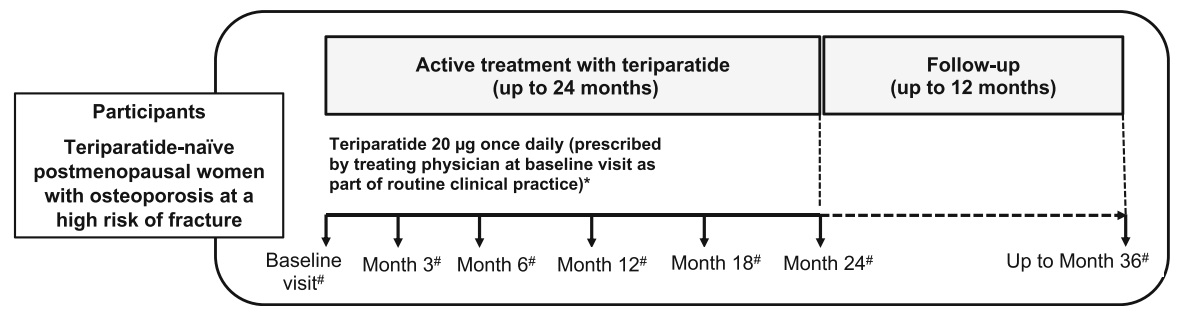

Fig. 1 ALAFOS study design. *The treating physicians were responsible for all decisions regarding diagnosis and treatment according to their clinical judgment and local medical care practices. "Patient observation and data collection were conducted during routine clinical visits 
Table 1 Baseline characteristics and reproductive history

\begin{tabular}{|c|c|c|c|c|c|}
\hline Characteristic & $\begin{array}{l}\text { Colombia } \\
(N=277)\end{array}$ & $\begin{array}{l}\text { Brazil } \\
(N=130)\end{array}$ & $\begin{array}{l}\text { Mexico } \\
(N=83)\end{array}$ & $\begin{array}{l}\text { Argentina } \\
(N=56)\end{array}$ & $\begin{array}{l}\text { All Patients Latin } \\
\text { America Subregion } \\
(N=546)\end{array}$ \\
\hline Age (years), mean (SD) & $72.7(9.8)$ & $68.6(10.0)$ & $67.8(11.0)$ & $72.4(8.4)$ & $71.0(10.1)$ \\
\hline Body mass index $\left(\mathrm{kg} / \mathrm{m}^{2}\right)$, mean (SD) & $25.1(3.7)$ & $24.8(4.5)$ & $25.6(3.4)$ & $25.3(4.0)$ & $25.2(3.9)$ \\
\hline \multicolumn{6}{|c|}{ Bone mineral density (T-score), mean (SD) } \\
\hline Lumbar spine & $-3.10(1.11)(n=185)$ & $-3.30(1.21)(n=105)$ & $-2.46(1.28)(n=73)$ & $-2.93(1.40)(n=50)$ & $-3.02(1.23)(n=413)$ \\
\hline Total hip & $-2.45(1.05)(n=50)$ & $-1.80(0.86)(n=64)$ & $-2.40(0.68)(n=58)$ & $-2.36(1.23)(n=27)$ & $-2.21(0.96)(n=199)$ \\
\hline Femoral neck & $-2.40(0.95)(n=137)$ & $-1.96(0.96)(n=74)$ & $-2.35(0.86)(n=28)$ & $-2.58(0.90)(n=39)$ & $-2.31(0.96)(n=278)$ \\
\hline $\begin{array}{l}\text { Patients older than } 40 \text { years with } \geq 1 \\
\text { previous low trauma fracture, } n(\%)\end{array}$ & $187(67.5 \%)$ & $67(51.5 \%)$ & $46(55.4 \%)$ & $43(76.8 \%)$ & $343(62.8 \%)$ \\
\hline \multicolumn{6}{|c|}{ Patients older than 40 years with previous low trauma fracture (by number of fractures), n (\%) } \\
\hline No fractures & $90(32.6 \%)$ & $63(48.8 \%)$ & $37(45.1 \%)$ & $13(23.2 \%)$ & $203(37.4 \%)$ \\
\hline 1 fracture & $105(38.0 \%)$ & $39(30.2 \%)$ & $36(43.9 \%)$ & $13(23.2 \%)$ & $193(35.5 \%)$ \\
\hline 2 fractures & $55(19.9 \%)$ & $15(11.6 \%)$ & $8(9.8 \%)$ & $13(23.2 \%)$ & $91(16.8 \%)$ \\
\hline 3 fractures & $13(4.7 \%)$ & $9(7.0 \%)$ & $1(1.2 \%)$ & $9(16.1 \%)$ & $32(5.9 \%)$ \\
\hline 4 fractures & $7(2.5 \%)$ & $1(0.8 \%)$ & $0(0.0 \%)$ & $1(1.8 \%)$ & $9(1.7 \%)$ \\
\hline 5 or more fractures & $6(2.2 \%)$ & $2(1.6 \%)$ & $0(0.0 \%)$ & $7(12.5 \%)$ & $15(2.8 \%)$ \\
\hline \multicolumn{6}{|l|}{ Previous fracture sites, n (\%) } \\
\hline Vertebral & $96(34.7 \%)$ & $28(21.5 \%)$ & $7(8.4 \%)$ & 35 (62.5\%) & $166(30.4 \%)$ \\
\hline Non-vertebral & 90 (32.5\%) & $28(21.5 \%)$ & $38(45.8 \%)$ & $20(35.7 \%)$ & $176(32.2 \%)$ \\
\hline Main non-vertebral ${ }^{a}$ & $70(25.3 \%)$ & $18(13.8 \%)$ & $26(31.3 \%)$ & $14(25.0 \%)$ & $128(23.4 \%)$ \\
\hline Hip & $23(8.3 \%)$ & $8(6.2 \%)$ & $1(1.2 \%)$ & $4(7.1 \%)$ & $36(6.6 \%)$ \\
\hline \multicolumn{6}{|c|}{ Reproductive history } \\
\hline $\begin{array}{l}\text { Age at onset of menopause (years), } \\
\text { mean (SD) }\end{array}$ & $48.7(5.2)$ & $45.9(6.6)$ & $46.6(4.9)$ & $47.2(5.0)$ & $47.5(5.6)$ \\
\hline $\begin{array}{l}\text { Number of fertile years }{ }^{b} \text {, median } \\
(Q 1, Q 3) \text {, years }\end{array}$ & $36.0(32,38)$ & $33.5(28,37)$ & $36.0(33,38)$ & $35.0(32,39)$ & $35.0(31,38)$ \\
\hline \multicolumn{6}{|l|}{ Parity ${ }^{c}, \mathrm{n}(\%)$ patients } \\
\hline 0 & 44 (15.9\%) & $15(11.5 \%)$ & 7 (8.4\%) & $11(19.6 \%)$ & $77(14.1 \%)$ \\
\hline 1 & $29(10.5 \%)$ & $7(5.4 \%)$ & $8(9.6 \%)$ & $10(17.9 \%)$ & $54(9.9 \%)$ \\
\hline 2 & $45(16.3 \%)$ & $31(23.8 \%)$ & $20(24.1 \%)$ & $17(30.4 \%)$ & $113(20.7 \%)$ \\
\hline 3 & $56(20.3 \%)$ & $23(17.7 \%)$ & $23(27.7 \%)$ & $11(19.6 \%)$ & $113(20.7 \%)$ \\
\hline 4 & $34(12.3 \%)$ & $18(13.8 \%)$ & $9(10.8 \%)$ & $5(8.9 \%)$ & $66(12.1 \%)$ \\
\hline 5 or more & $68(24.6 \%)$ & $36(27.7 \%)$ & $16(19.3 \%)$ & $2(3.6 \%)$ & $122(22.4 \%)$ \\
\hline Early menopause (< age 40), n (\%) & $12(4.3 \%)$ & $18(13.8 \%)$ & $5(6.0 \%)$ & $5(8.9 \%)$ & $40(7.3 \%)$ \\
\hline Surgical menopause, n (\%) & $46(17.8 \%)$ & $17(13.5 \%)$ & 35 (42.2\%) & $8(14.5 \%)$ & $106(20.3 \%)$ \\
\hline
\end{tabular}

$\mathrm{N}=$ total number of patients available; $\mathrm{n}=$ number of patients with valid (non-missing or unknown) values; $\mathrm{SD}=\mathrm{standard}$ deviation; $\mathrm{Q} 1=$ first quartile; Q3 = third quartile

${ }^{a}$ Radius, hip, humerus, tibia, pelvis and clavicle

${ }^{\mathrm{b}}$ Age at menopause - age at menstruation

'Number of times given birth

Note: Percentages are calculated using $n$, the number of valid (not missing or unknown) responses for each item

\section{Bone mineral density and fracture history}

At baseline, the mean (SD) bone mineral density (BMD) T-scores for the LA subregional cohort were-3.02 (1.23) for the lumbar spine, $-2.21(0.96)$ for total hip, and - 2.31 (0.96) for femoral neck (Table 1). A large proportion of patients $(62.8 \%)$ reported having a history of low trauma fracture after the age of 40 years; the corresponding values for the four individual countries were 67.5\% (Colombia), 51.5\% (Brazil), 55.4\% (Mexico), and $76.8 \%$ (Argentina). In the overall LA cohort, $27.2 \%$ of patients had experienced $\geq 2$ fragility fractures after the age of 40 years (29.3\% for Colombia, 21.0\% for Brazil, $11.0 \%$ 
for Mexico, and 53.6\% for Argentina; Fig. 2). A previous history of vertebral fractures was reported by $30.4 \%$ of patients, while non-vertebral fractures were reported by $32.2 \%$ of patients (Table 1 ).

\section{Risk factors for osteoporosis and fractures}

Some of the common risk factors for osteoporosis and fractures are summarized in Table 2. Approximately $30 \%$ of patients in the overall LA cohort had a maternal history of osteoporosis or hip fracture; this number was higher for Brazil and Mexico (40.2 and 39.7\%, respectively). Around $50 \%$ of patients had problems with vision, and $39.7 \%$ of patients reported having experienced $\geq 1$ fall in the past year. In the overall LA cohort, $57.2 \%$ of patients reported using the support of arms while standing up from a chair (Table 2).

\section{Current comorbidities and concomitant medications}

Table 2 also summarizes the most commonly reported comorbidities and concomitant medications. Hypertension was the most common comorbidity in the overall LA subregion (46.2\%) as well as in Colombia (44.8\%), Brazil (51.2\%), Mexico (44.6\%) and Argentina (44.6\%). Rheumatoid arthritis or other rheumatologic conditions were reported by $22.8 \%$ of patients and type 2 diabetes mellitus was reported by $8.3 \%$ of patients. Glucocorticoids were used by $6.2 \%$ of patients in the overall LA cohort (prednisone daily equivalent dose $\geq 7.5 \mathrm{mg}$ for $\geq 3$
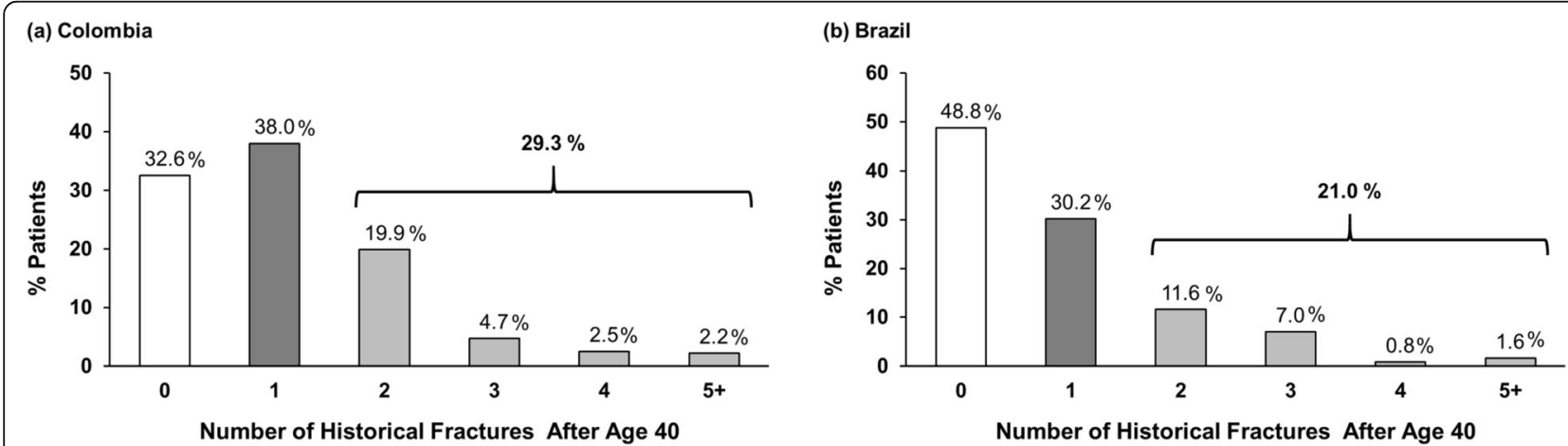

(c) Mexico

(d) Argentina

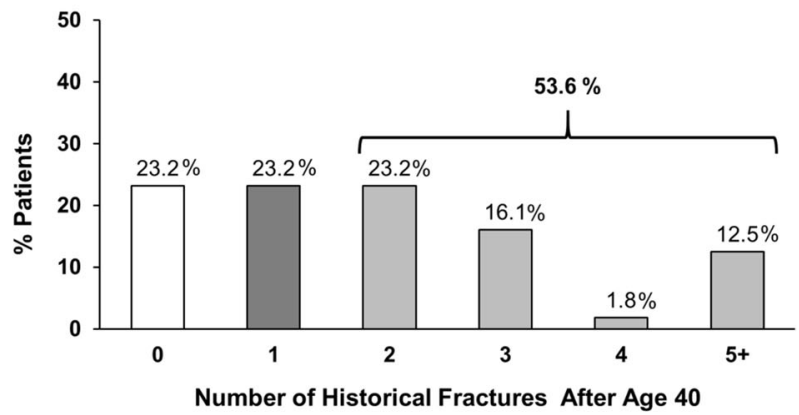

(e) All Patients - Latin America subregion

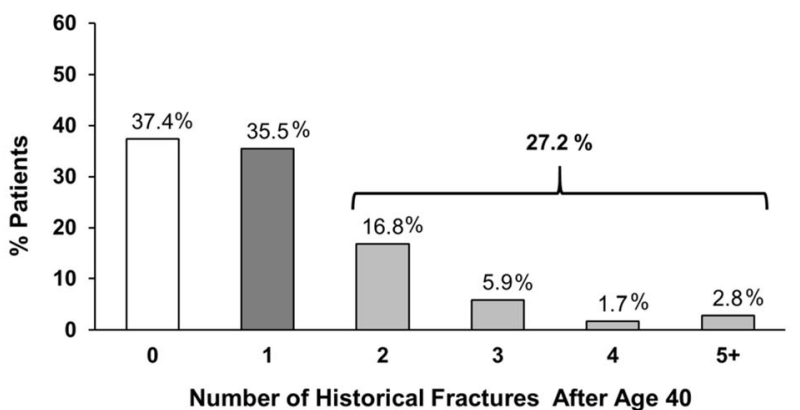

Fig. 2 Percent of patients with osteoporotic fractures after 40 years of age. a Colombia $(N=277) ;(\mathbf{b})$ Brazil $(N=130)$; (c) Mexico $(N=83)$; (d) Argentina $(N=56)$; (e) All Patients - Latin America subregion $(N=546)$. Note: Percentages are calculated using $n$, the number of valid (not missing or unknown) responses for each item 
Table 2 Risk factors for osteoporosis and fractures, current comorbidities, and concomitant medications

\begin{tabular}{|c|c|c|c|c|c|}
\hline Characteristic & $\begin{array}{l}\text { Colombia } \\
(N=277)\end{array}$ & $\begin{array}{l}\text { Brazil } \\
(N=130)\end{array}$ & $\begin{array}{l}\text { Mexico } \\
(N=83)\end{array}$ & $\begin{array}{l}\text { Argentina } \\
(N=56)\end{array}$ & $\begin{array}{l}\text { All Patients Latin } \\
\text { America Subregion } \\
(N=546)\end{array}$ \\
\hline Maternal history of osteoporosis or hip fracture, $\mathrm{n}(\%)$ & $57(23.4 \%)$ & $37(40.2 \%)$ & $23(39.7 \%)$ & $14(30.4 \%)$ & $131(29.8 \%)$ \\
\hline Sight problems, n (\%) & $133(50.6 \%)$ & $84(68.9 \%)$ & $22(26.5 \%)$ & $24(42.9 \%)$ & $263(50.2 \%)$ \\
\hline Patients experiencing falls in the past year, $\mathrm{n}(\%)$ & $103(38.6 \%)$ & $39(31.5 \%)$ & $44(62.9 \%)$ & $18(34.0 \%)$ & $204(39.7 \%)$ \\
\hline \multicolumn{6}{|l|}{ Number of falls in the past year, $\mathrm{n}(\%)$} \\
\hline No falls & $164(61.4 \%)$ & $85(68.5 \%)$ & $26(37.1 \%)$ & $35(66.0 \%)$ & $310(60.3 \%)$ \\
\hline 1 fall & $62(23.2 \%)$ & $24(19.4 \%)$ & $14(20.0 \%)$ & $10(18.9 \%)$ & $110(21.4 \%)$ \\
\hline 2 falls & $21(7.9 \%)$ & $7(5.6 \%)$ & $9(12.9 \%)$ & $3(5.7 \%)$ & $40(7.8 \%)$ \\
\hline 3 or more falls & $20(7.5 \%)$ & $8(6.5 \%)$ & $21(30.0 \%)$ & $5(9.4 \%)$ & $54(10.5 \%)$ \\
\hline Hours of exercise per week, mean (SD) & $2.6(8.3)$ & $1.2(1.8)$ & $2.1(2.6)$ & $2.0(2.4)$ & $2.1(6.2)$ \\
\hline Use of arms when standing up from a chair, n (\%) & $159(58.2 \%)$ & $74(59.2 \%)$ & $57(68.7 \%)$ & 17 (30.4\%) & $307(57.2 \%)$ \\
\hline Immobilized for > 12 months, n (\%) & $3(1.1 \%)$ & $6(4.8 \%)$ & $1(1.2 \%)$ & $1(1.8 \%)$ & $11(2.1 \%)$ \\
\hline Currently smoking, n (\%) & $16(5.9 \%)$ & $9(7.0 \%)$ & $10(12.0 \%)$ & $4(7.1 \%)$ & $39(7.2 \%)$ \\
\hline Alcoholic drinks per week, mean (SD) & $0.2(1.2)$ & $0.3(1.1)$ & $0.2(0.8)$ & $0.4(1.9)$ & $0.2(1.2)$ \\
\hline Caffeinated drinks per week, mean (SD) & $8.1(9.6)$ & $11.0(13.6)$ & $7.2(6.0)$ & $3.4(5.0)$ & $8.2(10.2)$ \\
\hline \multicolumn{6}{|l|}{ Patients with current comorbidities ${ }^{a}, \mathrm{n}(\%)$} \\
\hline Hypertension & $124(44.8 \%)$ & $66(51.2 \%)$ & $37(44.6 \%)$ & $25(44.6 \%)$ & $252(46.2 \%)$ \\
\hline Rheumatoid arthritis or other rheumatologic conditions & $81(29.5 \%)$ & $17(13.4 \%)$ & $19(22.9 \%)$ & $6(10.9 \%)$ & $123(22.8 \%)$ \\
\hline Type 2 diabetes mellitus & $18(6.5 \%)$ & $18(14.3 \%)$ & $8(9.6 \%)$ & $1(1.8 \%)$ & $45(8.3 \%)$ \\
\hline \multicolumn{6}{|l|}{ Concomitant medications ${ }^{\mathrm{b}}, \mathrm{n}(\%)$} \\
\hline Antihypertensives & $83(30.0 \%)$ & $61(46.9 \%)$ & $30(36.1 \%)$ & $17(30.4 \%)$ & $191(35.0 \%)$ \\
\hline Thyroid hormones & $63(22.7 \%)$ & $18(13.8 \%)$ & $18(21.7 \%)$ & $17(30.4 \%)$ & $116(21.2 \%)$ \\
\hline Antidepressants & $15(5.4 \%)$ & $24(18.5 \%)$ & $1(1.2 \%)$ & $3(5.4 \%)$ & $43(7.9 \%)$ \\
\hline Insulins/oral hypoglycemics & $20(7.2 \%)$ & $14(10.8 \%)$ & $5(6.0 \%)$ & $1(1.8 \%)$ & $40(7.3 \%)$ \\
\hline Glucocorticoids $^{c}$ & $12(7.5 \%)$ & 7 (8.0\%) & $0(0.0 \%)$ & 1 (2.9\%) & $20(6.2 \%)$ \\
\hline
\end{tabular}

$\mathrm{N}=$ total number of patients available; $\mathrm{n}=$ number of patients with valid (non-missing or unknown) values; $\mathrm{SD}=\mathrm{standard}$ deviation

${ }^{a}$ The three most frequently reported comorbidities in the overall ALAFOS study cohort [10] are listed here

${ }^{b}$ Concomitant medications related to risk of osteoporosis and falls taken by $>5 \%$ of all patients in the overall Latin American subregional cohort at baseline. Other medications included oral anticoagulants/heparin (1.3\% of all patients), benzodiazepines (3.8\%), antiarrhythmics (4.8\%), and anticonvulsants (3.3\%)

'Duration of therapy $\geq 3$ months or a prednisone daily equivalent dose $\geq 7.5 \mathrm{mg}$

Note: Percentages are calculated using $n$, the number of valid (not missing or unknown) responses for each item

months); the use of glucocorticoids was lower in Argentina (2.9\%) and Mexico (0.0\%; Table 2).

\section{Osteoporosis and back pain therapies}

A large proportion of patients in the overall LA cohort (70.9\%) had used osteoporosis medications prior to initiating teriparatide (Table 3). Patients from Argentina reported the highest use of osteoporosis medications in the past (92.9\%). The most commonly used class of antiresorptive osteoporosis medications was bisphosphonates (34.8\% of patients in the overall LA cohort had taken at least one bisphosphonate); bisphosphonate use was higher in Mexico (55.4\%) than in the other countries in LA (Colombia [26.4\%], Brazil [37.7\%], and Argentina [39.3\%]). More patients in Argentina (69.6\%) reported using calcium than other participant countries from the LA subregion (Brazil [50.0\%], Colombia [43.0\%], and Mexico
[41.0\%]). A similar trend was noted for vitamin D use (Argentina [80.4\%], Brazil [46.9\%], Mexico [37.3\%], and Colombia [29.6\%]). About $31 \%$ of patients in the overall LA cohort reported using $\geq 1$ medication for back pain in the past $24 \mathrm{~h}$ (Table 3); this figure was highest for patients from Argentina (46.4\%) and lowest for Brazil (17.7\%). The most commonly used medication for back pain in the overall LA cohort was paracetamol (16.3\%) followed by nonsteroidal anti-inflammatory drugs (9.2\%; Table 3$)$.

\section{Health-related quality of life and back pain}

The baseline HRQoL scores for the overall LA subregion and the four participant countries are shown in Table 4. The median (Q1, Q3) EQ-5D-5L Visual Analog Scale (VAS) score for perceived health status was $70(50,80)$ in the overall LA cohort; this was generally consistent across the four participant countries (Table 4). The median (Q1, 
Table 3 Previous use of osteoporosis and analgesic medications

\begin{tabular}{|c|c|c|c|c|c|}
\hline Characteristic & $\begin{array}{l}\text { Colombia } \\
(N=277)\end{array}$ & $\begin{array}{l}\text { Brazil } \\
(N=130)\end{array}$ & $\begin{array}{l}\text { Mexico } \\
(N=83)\end{array}$ & $\begin{array}{l}\text { Argentina } \\
(N=56)\end{array}$ & $\begin{array}{l}\text { All Patients Latin } \\
\text { America Subregion } \\
(N=546)\end{array}$ \\
\hline Past use of osteoporosis medication ${ }^{\mathrm{a}}, \mathrm{n}(\%)$ & $181(65.3 \%)$ & $96(73.8 \%)$ & $58(69.9 \%)$ & $52(92.9 \%)$ & $387(70.9 \%)$ \\
\hline \multicolumn{6}{|l|}{ Number of previous osteoporosis medications, n (\%) } \\
\hline 0 & $96(34.7 \%)$ & $34(26.2 \%)$ & $25(30.1 \%)$ & $4(7.1 \%)$ & $159(29.1 \%)$ \\
\hline 1 & $95(34.3 \%)$ & $29(22.3 \%)$ & $12(14.5 \%)$ & $10(17.9 \%)$ & $146(26.7 \%)$ \\
\hline 2 & $60(21.7 \%)$ & $39(30.0 \%)$ & $14(16.9 \%)$ & $23(41.1 \%)$ & $136(24.9 \%)$ \\
\hline 3 & $20(7.2 \%)$ & $24(18.5 \%)$ & $11(13.3 \%)$ & $17(30.4 \%)$ & $72(13.2 \%)$ \\
\hline 4 & $5(1.8 \%)$ & $4(3.1 \%)$ & $17(20.5 \%)$ & $1(1.8 \%)$ & $27(4.9 \%)$ \\
\hline 5 or more & $1(0.4 \%)$ & $0(0.0 \%)$ & $4(4.8 \%)$ & $1(1.8 \%)$ & $6(1.1 \%)$ \\
\hline \multicolumn{6}{|l|}{ Previous pharmacotherapy for osteoporosis ${ }^{\mathrm{b}}, \mathrm{n}(\%)$} \\
\hline Alendronate & $31(11.2 \%)$ & $37(28.5 \%)$ & $20(24.1 \%)$ & $6(10.7 \%)$ & $94(17.2 \%)$ \\
\hline Ibandronate & $23(8.3 \%)$ & $3(2.3 \%)$ & $9(10.8 \%)$ & $11(19.6 \%)$ & $46(8.4 \%)$ \\
\hline Risedronate & $4(1.4 \%)$ & $10(7.7 \%)$ & $4(4.8 \%)$ & $6(10.7 \%)$ & $24(4.4 \%)$ \\
\hline Zoledronate & $21(7.6 \%)$ & $6(4.6 \%)$ & $23(27.7 \%)$ & $1(1.8 \%)$ & $51(9.3 \%)$ \\
\hline Other bisphosphonates & $1(0.4 \%)$ & $1(0.8 \%)$ & $1(1.2 \%)$ & $2(3.6 \%)$ & $5(0.9 \%)$ \\
\hline Any one or more bisphosphonates & $73(26.4 \%)$ & $49(37.7 \%)$ & $46(55.4 \%)$ & $22(39.3 \%)$ & $190(34.8 \%)$ \\
\hline Calcitonin & $3(1.1 \%)$ & $3(2.3 \%)$ & $1(1.2 \%)$ & $0(0.0 \%)$ & $7(1.3 \%)$ \\
\hline Calcium only & $119(43.0 \%)$ & $65(50.0 \%)$ & $34(41.0 \%)$ & $39(69.6 \%)$ & $257(47.1 \%)$ \\
\hline Denosumab & $13(4.7 \%)$ & $0(0.0 \%)$ & $8(9.6 \%)$ & $5(8.9 \%)$ & $26(4.8 \%)$ \\
\hline Raloxifene & $0(0.0 \%)$ & $1(0.8 \%)$ & $3(3.6 \%)$ & $0(0.0 \%)$ & $4(0.7 \%)$ \\
\hline Strontium ranelate & $2(0.7 \%)$ & $4(3.1 \%)$ & $1(1.2 \%)$ & $2(3.6 \%)$ & $9(1.6 \%)$ \\
\hline Vitamin D only & $82(29.6 \%)$ & $61(46.9 \%)$ & $31(37.3 \%)$ & $45(80.4 \%)$ & $219(40.1 \%)$ \\
\hline Use of $\geq 1$ back pain medication over the past $24 \mathrm{~h}, \mathrm{n}(\%)$ & $94(33.9 \%)$ & $23(17.7 \%)$ & $24(28.9 \%)$ & $26(46.4 \%)$ & $167(30.6 \%)$ \\
\hline \multicolumn{6}{|l|}{ Specific back pain medications, n (\%) } \\
\hline NSAIDs & $11(4.0 \%)$ & $6(4.6 \%)$ & $19(22.9 \%)$ & $14(25.0 \%)$ & $50(9.2 \%)$ \\
\hline Paracetamol & $66(23.8 \%)$ & $5(3.8 \%)$ & $10(12.0 \%)$ & $8(14.3 \%)$ & $89(16.3 \%)$ \\
\hline Opioids & $22(7.9 \%)$ & $2(1.5 \%)$ & $0(0.0 \%)$ & $4(7.1 \%)$ & $28(5.1 \%)$ \\
\hline Paracetamol and opioid combination & $2(0.7 \%)$ & $0(0.0 \%)$ & $0(0.0 \%)$ & $0(0.0 \%)$ & $2(0.4 \%)$ \\
\hline
\end{tabular}

$\mathrm{N}=$ total number of patients available; $\mathrm{n}=$ number of patients with valid (non-missing or unknown) values; NSAIDs = nonsteroidal anti-inflammatory drugs ${ }^{a}$ This includes ongoing medications as well as those stopped before baseline

${ }^{b}$ Prior osteoporosis medications taken by $>0.5 \%$ of all patients in the overall Latin American subregional cohort

Note: Percentages are calculated using $n$, the number of valid (not missing or unknown) responses for each item

Q3) EQ-5D-5 L utility total score was $0.65(0.53,0.77)$ for the overall LA cohort. A substantial number of patients reported experiencing severe/extreme problems on the individual domain scores of the EQ-5D-5 L questionnaire (mobility, self-care, usual activities, pain/discomfort and anxiety/depression; Table 4). The mean (SD) back pain numeric rating scale scores for the overall LA cohort were 4.3 (3.4) for worst pain in the last $24 \mathrm{~h}$ and 3.7 (3.1) for average pain in the last $24 \mathrm{~h}$ (Table 4 ).

\section{Discussion}

The ALAFOS is a large observational study evaluating teriparatide use in postmenopausal women with osteoporosis during routine clinical practice in 20 countries across the world [10]. The LA subregional analysis of the ALAFOS study is the first analysis evaluating teriparatide in a community setting in the Latin American population.

A recent consensus paper discussing treatment and prevention of osteoporosis in LA [1] states that osteoporosis treatment should be initiated in patients with low BMD (Tscore $\leq-2.5$ at the lumbar spine, total hip, or femoral neck), or a history of fragility fracture, or in osteopenic patients with a FRAX ${ }^{\circ}$ score above the designated interventional level $[1,11,12]$. Country-specific validated $\mathrm{FRAX}^{\bullet}$ tools are available for several Latin American countries [1, 2, 11]. Currently, several antiresorptive therapies such as bisphosphonates, denosumab, selective estrogen receptor modulators, and hormone replacement therapy are available for the treatment of osteoporosis in LA. However, teriparatide is the only bone-forming therapy that is currently available 
Table 4 Health-related quality of life scores at baseline

\begin{tabular}{|c|c|c|c|c|c|}
\hline Characteristic & $\begin{array}{l}\text { Colombia } \\
(N=277)\end{array}$ & $\begin{array}{l}\text { Brazil } \\
(N=130)\end{array}$ & $\begin{array}{l}\text { Mexico } \\
(N=83)\end{array}$ & $\begin{array}{l}\text { Argentina } \\
(N=56)\end{array}$ & $\begin{array}{l}\text { All Patients Latin } \\
\text { America Subregion } \\
(N=546)\end{array}$ \\
\hline \multicolumn{6}{|l|}{$\overline{\text { EQ-5D-5 L-VAS score }}{ }^{a}$} \\
\hline Median (Q1, Q3) & $70.0(50.0,80.0)$ & $65.0(50.0,80.0)$ & $60.0(45.0,75.0)$ & $70.0(60.0,80.0)$ & $70.0(50.0,80.0)$ \\
\hline Mean (SD) & $67.0(20.5)$ & $62.6(22.2)$ & $59.2(21.4)$ & $70.5(16.7)$ & $65.2(20.9)$ \\
\hline \multicolumn{6}{|l|}{ EQ-5D-5 L severe/extreme problems ${ }^{\mathrm{b}}, \mathrm{n}(\%)$} \\
\hline Mobility & $24(8.7 \%)$ & $13(10.0 \%)$ & $3(3.6 \%)$ & $3(5.4 \%)$ & $43(7.9 \%)$ \\
\hline Self-care & $17(6.2 \%)$ & $4(3.1 \%)$ & $3(3.6 \%)$ & $0(0.0 \%)$ & $24(4.4 \%)$ \\
\hline Usual activities & $35(12.7 \%)$ & $10(7.7 \%)$ & $4(4.8 \%)$ & $3(5.4 \%)$ & $52(9.5 \%)$ \\
\hline Pain/discomfort & $47(17.1 \%)$ & $22(16.9 \%)$ & $13(15.7 \%)$ & $6(10.7 \%)$ & $88(16.2 \%)$ \\
\hline Anxiety/depression & $34(12.3 \%)$ & $15(11.5 \%)$ & $3(3.6 \%)$ & $2(3.6 \%)$ & $54(9.9 \%)$ \\
\hline EQ-5D-5 L - Utility Total Score, median (Q1, Q3) & $0.65(0.50,0.78)$ & $0.64(0.52,0.74)$ & $0.65(0.60,0.77)$ & $0.71(0.59,0.80)$ & $0.65(0.53,0.77)$ \\
\hline \multicolumn{6}{|l|}{ Back Pain Numeric Rating Scale ${ }^{c}$} \\
\hline \multicolumn{6}{|l|}{ Worst pain in the last $24 \mathrm{~h}$} \\
\hline Median (Q1, Q3) & $3.0(0.0,7.0)$ & $5.0(3.0,8.0)$ & $7.0(3.0,8.0)$ & $5.0(0.0,7.0)$ & $5.0(0.0,8.0)$ \\
\hline Mean (SD) & $3.6(3.4)$ & $5.1(3.3)$ & $5.5(3.3)$ & $4.2(3.4)$ & $4.3(3.4)$ \\
\hline \multicolumn{6}{|l|}{ Average pain in the last $24 \mathrm{~h}$} \\
\hline Median (Q1, Q3) & $3.0(0.0,6.0)$ & $5.0(2.0,7.0)$ & $3.0(2.0,5.0)$ & $3.0(0.0,7.0)$ & $4.0(0.0,6.0)$ \\
\hline Mean (SD) & $3.4(3.3)$ & $4.7(3.0)$ & $3.4(2.5)$ & $3.6(3.0)$ & $3.7(3.1)$ \\
\hline
\end{tabular}

$\mathrm{N}=$ total number of patients; $\mathrm{n}=$ number of patients with valid (non-missing or unknown) values; $\mathrm{Q} 1=$ first quartile; $\mathrm{Q} 3=$ third quartile; VAS=Visual Analog Scale ${ }^{a} \mathrm{~A} 100-\mathrm{mm}$ visual analog scale was used to indicate perceived overall health status $(0=$ the worst health you can imagine; $100=$ the best health you can imagine) bor the "mobility," "self-care," and "usual activities" domains, extreme problems refers to inability to move, inability to take care of self and inability to perform usual activities, respectively

${ }^{\mathrm{C}}$ Back pain was self-assessed by patients on a rating scale of 0 to $10(0=$ no back pain; $10=$ worst possible back pain $)$

Note: Percentages are calculated using $n$, the number of valid (not missing or unknown) responses for each item

[1]. The Iberoamerican Consensus on Osteoporosis recommends that teriparatide can be used in postmenopausal women $\geq 65$ years with confirmed osteoporosis and prevalent vertebral fracture [13]. Several country-specific guidelines for diagnosis and treatment of osteoporosis are available and the recommendations regarding teriparatide use are generally similar [1]. The 2017 Colombian Consensus on Osteoporosis recommends teriparatide in patients with vertebral fragility fractures ( 1 severe or $\geq 2$ with any grade of severity), or in patients with lumbar spine $\mathrm{T}$ score $\leq-3.5$ [14]. The Argentine Guidelines for Osteoporosis recommend teriparatide as first-line therapy in men or women with a high risk for osteoporotic fractures (including those with a history of clinical or radiological, vertebral fractures), in patients with other fragility fractures associated with low BMD values, or in patients with very low BMD (T-score < - 3) without history of fractures [15]. Teriparatide is also recommended in patients who have had a suboptimal response to antiresorptive therapy [15]. The Brazilian Society of Rheumatology and the Brazilian Medical Association recommend that teriparatide can be used for the treatment of osteoporosis in postmenopausal women at high risk of fractures, those with previous fractures, or those who did not have adequate response to other forms of osteoporosis treatment [16]. It is also important to note that access to teriparatide may vary across countries. For example, although guidelines recommend teriparatide in Brazil [16], it has not been included in the National Clinical Protocol and Osteoporosis Therapeutic Guidelines published by the Ministry of Health to be reimbursed by the Brazilian government program. The use of teriparatide in Brazil in the general population occurs from states where local policy reimburses teriparatide after careful revision, private medical insurance that covers teriparatide treatment and in patients who demand justice for access to the treatment [17]. In Mexico, teriparatide is not included in the guidelines for the National Healthcare System [18]. In this case, use of teriparatide in the general population may be restricted to those who have private insurance policies, which cover teriparatide treatment. This LA subregional analysis of the ALAFOS study provides useful insights into the patient population that is currently being prescribed teriparatide in the four participant countries in a realworld setting.

In this subregional analysis of the ALAFOS baseline data, we found that patients who are prescribed teriparatide in LA are usually elderly women (average age: 71 years) with severe osteoporosis who are at a high risk of fracture. This is in line with the approved labels for 
teriparatide in major geographies such as Europe and the United States, which state that teriparatide is indicated for the treatment of osteoporosis in postmenopausal women at an increased risk for fracture [8,9]. The patients who were prescribed teriparatide in our LA cohort typically had a high BMI with low BMD values, especially at the lumbar spine. Many patients $(\sim 30 \%)$ had a maternal history of osteoporosis/hip fracture and $>60 \%$ of patients had experienced a fragility fracture themselves after the age of 40 years. In general, these findings are similar to those observed in the overall ALAFOS study population [10], as well as other observational studies conducted in Europe and the United States [19-23].

Across the LA subregion, there was wide variation among the participant countries with respect to the fracture history at baseline. The proportion of patients who had experienced at least one fragility fracture after 40 years of age at baseline ranged from $51.5 \%$ in Brazil to $76.8 \%$ in Argentina. The percentage of patients with two or more fragility fractures after 40 years of age ranged from $11.0 \%$ in Mexico to $53.6 \%$ in Argentina. With respect to the previous fracture sites, vertebral fractures were more common than non-vertebral fractures in Argentina (vertebral fractures: $62.5 \%$ of patients; nonvertebral fractures: $35.7 \%$ ), while the opposite was observed in Mexico (vertebral fractures: $8.4 \%$ of patients; non-vertebral fractures: $45.8 \%)$. However, it is important to note that patients were not uniformly distributed across countries. Moreover, these differences in the previous fracture status may reflect a patient selection bias based on the medical specialties of the participant sites.

The Brazilian Osteoporosis Study (BRAZOS) identified advanced age, early menopause, sedentary lifestyle, family history of hip fracture, and recurrent falls as important risk factors for osteoporosis [24]. Many patients in this ALAFOS LA subregional analysis presented a high prevalence of these risk factors at baseline such as early menopause (7.3\%), surgical menopause (20.3\%), immobilization for $>12$ months (2.1\%), maternal history of osteoporosis/hip fracture (29.8\%), and falls in the past year (39.7\%).

Back pain was frequent among patients in the LA subregion at baseline, and around $30 \%$ of patients were taking $\geq 1$ medication for relief of back pain before enrollment. This observation was similar to the overall ALAFOS study cohort [10]. Previous observational studies have also reported severe and disabling back pain at baseline in patients with osteoporosis who were treated with teriparatide in Europe [20,22]. The LA subregional analysis of the ALAFOS found that use of back pain medications was highest in Argentina, probably reflecting the higher prevalence of previous fractures in the patients enrolled from this country. The use of osteoporosis medications, calcium, and vitamin D at baseline was also highest in Argentina, while bisphosphonate use at baseline was highest in Mexico.

A recent study conducted by Cano-Gutiérrez, et al. using data from the SABE Bogotá Study, found a correlation between the presence of osteoporosis and impairment in functionality in 2000 people aged 60 years or older [25]. Many patients in the overall LA subregion as well as in all participant countries reported a low HRQoL at baseline as indicated by the low EQ-5D-5 L VAS and utility total scores. Several patients in the LA subregional cohort reported experiencing severe to extreme problems with respect to mobility, self-care, usual activities, pain/discomfort, and anxiety/depression. However, the proportions of patients reporting severe/extreme problems in the LA subregion were lower than those in the overall ALAFOS study cohort [10]. Similarly, within the LA subregion, more patients from Colombia and Brazil reported severe/extreme problems compared to patients from Argentina. These findings provide a baseline evaluation of the HRQoL and back pain parameters in patients with osteoporosis. The ALAFOS study will further evaluate HRQoL over time on teriparatide treatment. We believe this information is important since to our knowledge, there are no other studies reporting HRQoL in patients with osteoporosis in Latin America.

Osteoporosis continues to pose a major healthcare concern worldwide as well as in LA. The LAVOS study, a population-based study of vertebral fractures in LA, found that the prevalence ( $95 \% \mathrm{CI}$ ) of radiographic vertebral fractures in women between 50 and 79 years of age was 13.80 (10.03-17.56) in Argentina, 10.79 (7.3414.23) in Brazil, 10.72 (6.94-14.50) in Colombia, and 13.26 (9.46-17.07) in Mexico [6]. The 2012 Latin American regional audit reported that 2,609,858 and 1,423,559 Colombian women $\geq 50$ years of age were living with osteopenia and osteoporosis, respectively; by the year 2050, these numbers could increase to 3,852,200 and 2, 101,000 for osteopenia and osteoporosis, respectively [26]. A survey conducted by the Mexican Institute of Social Security predicted that the number of hip fractures per year in Mexico is likely to increase from 29,732 in the year 2005 to 155,874 in 2050; this increase is possibly related to demographic changes, even if there is no increase in the age- and sex-specific incidence of hip fractures [27]. As a result of changing demographics, increasing elderly population, and changing lifestyles and disease patterns, the burden of osteoporosis in the LA region is expected to increase further over the years along with a corresponding increase in the associated costs $[1,28]$.

While discussing the epidemiology and patterns of treatment of osteoporosis in the LA region, it is important to note that LA region constitutes a very diverse mix of ethnicities including native Indians, Caucasians from 
Europe, Africans as well as Asians [28]. There is wide variation between and within countries in socioeconomic conditions of the population and availability of good public healthcare systems. There are also differences with respect to access to private insurance systems, which are usually expensive. All these factors ultimately affect the availability of good quality healthcare in this region [1]. Observational studies have been valuable tools to gather information about real-world effectiveness of medicines, region/country-specific factors affecting the usage of medicines, local treatment practices, and patient perceptions. We believe that this subregional analysis of the ALAFOS study will provide physicians, payers, healthcare providers and governmental health agencies useful data about real-world use of teriparatide in LA including information about the profiles of patients who are prescribed teriparatide, their baseline risk factors, HRQoL measures, and the effectiveness of teriparatide over the course of treatment in the real world.

\section{Strengths and limitations}

The strength of this study is that it is the first observational, naturalistic study providing real-world data reflecting actual use of teriparatide in LA, but there are several limitations to this analysis. The ALAFOS is a single-arm, observational study. The sample size in each individual country is relatively small. Patients are not uniformly distributed across countries, and they may not truly represent the general population of that country. The study uses patient-reported data for information such as history of fractures/falls, comorbid conditions and concomitant medications, and thus there could be chances of recall bias. In case of the HRQoL outcomes, there could also be a possibility of perception bias.

\section{Conclusions}

This LA subregional analysis of the ALAFOS study is the first observational study evaluating use of teriparatide in a community setting in LA. This study will provide useful real-world insights into the similarities and differences in the patterns of prescription of teriparatide across four countries in LA. This is especially important in light of the increasing prevalence and burden of osteoporosis in this region. Our baseline analysis revealed that patients who are currently being prescribed teriparatide in LA are elderly women with osteoporosis at a high risk of fracture who are suffering from back pain and poor HRQoL. The proportions of patients reporting severe/extreme problems on the EQ-5D-5L individual domains in this subregional analysis were lower than those observed in the overall ALAFOS study population. Subsequent results from the ALAFOS study would provide further insights on real-world effectiveness of teriparatide. This information would help healthcare providers, physicians, health policy makers, and payers in the effective management of osteoporosis.

\begin{abstract}
Abbreviations
ALAFOS: Asia and Latin America Fracture Observational Study; BMD: bone mineral density; BMI: body mass index; BRAZOS: Brazilian Osteoporosis Study; Cl: confidence interval; HRQoL: health-related quality of life; LA: Latin America; LAVOS: Latin American Vertebral Osteoporosis Study; Q1: first quartile; Q3: third quartile; rhPTH(1-34): recombinant human parathyroid hormone analog; SD: standard deviation; VAS: Visual Analog Scale
\end{abstract}

\section{Acknowledgments}

The authors thank Fernando Marin (MD, PhD), global study physician, Thomas Moll (PhD, MBA), clinical trial manager, Alan Brnabic (MSc), study statistician, and Sheetal Pradhan (MD), medical writer, for their contributions to this manuscript. All are employees of Eli Lilly and Company.

\section{Authors' contributions}

JLC, GMM, NC, AM, JFM, MLG and LGO were involved in recruitment of patients who participated in the study. All authors were involved in analysis and interpretation of the data, reviewing and revising the paper critically for intellectual content. All authors have approved the version to be published and agree to be accountable for all aspects of the work.

\section{Funding}

Eli Lilly and Company sponsored the ALAFOS study (including design of the study and collection, analysis, and interpretation of data and writing the manuscript). Unique study identifier for the ALAFOS study: B3D-MC-B026.

\section{Availability of data and materials}

The datasets generated during and/or analysed during the current study are available from the corresponding author on reasonable request.

\section{Ethics approval and consent to participate}

We declare that this study has been performed in accordance with Declaration of Helsinki and was approved by the appropriate local body. All participants have signed the informed consent form.

\section{Consent for publication}

Not applicable.

\section{Competing interests}

JLC-B reports having received lecture fees from Eli Lilly. GMM is an investigator of the ALAFOS study at Eli Lilly and Company. NC is an investigator of the ALAFOS study at Eli Lilly and Company. She is also a speaker for Eli Lilly and Company; she has participated as a principal investigator in phase III clinical studies and has served on the advisory board for Eli Lilly and Company. She has received fees for research from Lilly. She has also participated in clinical studies as principal investigator and speaker for Merck Sharp \& Dohme, Novartis of Colombia, Pfizer, Amgen, and Biopas. She has no employment relationship with any of these organizations. AM is a speaker for Lilly, Amgen and FARMA de Colombia. JFM is a speaker for Lilly and has received fees for research from Lilly. MLG is an investigator of the ALAFOS study at Eli Lilly and Company. She is also a speaker for Eli Lilly and Company. LGO is an investigator of the ALAFOS study at Eli Lilly and Company; he is also a speaker for Eli Lilly and Company and an author on publications from Eli Lilly and Eurofarma; he also serves on the advisory board of UCB (Belgian Chemical Union) and the board of directors for Eurofarma. MSC, ACC, VI, and SF are employees of Eli Lilly and Company.

\section{Author details}

${ }^{1}$ Faculty of Medicine, Universidade Católica de Brasília, Brasilia, Brazil. ${ }^{2}$ Hospital General de Mexico, Mexico City, Mexico. ${ }^{3}$ Riesgo de Fractura CAYRE, Bogotá, Colombia. ${ }^{4}$ Sociedad de Cirugía de Bogotá - Hospital Universitario de San José, Bogotá, Colombia. ${ }^{5}$ Reumalab, Medellín, Colombia. ${ }^{6}$ Sanatorio Municipal Dr. Julio Mendez, Buenos Aires, Argentina. ${ }^{7}$ Faculty of Medicine, Universidade Federal de Goias, Goiania, Brazil. ${ }^{8}$ Eli Lilly do Brasil, São Paulo, Brazil. ${ }^{9}$ Eli Lilly and Company de Mexico, Mexico City, Mexico. ${ }^{10}$ Eli Lilly Interamerica, Transversal 18 No. 96-41, Piso 6, Bogotá, Colombia. ${ }^{11}$ Pain and Palliative Care Unit, Universidad de la Sabana, Bogotá, Colombia. 
Received: 26 April 2019 Accepted: 26 September 2019

Published online: 08 November 2019

\section{References}

1. Albergaria $B H$, Chalem M, Clark P, Messina OD, Pereira RMR, Vidal LF. Consensus statement: osteoporosis prevention and treatment in Latin America — current structure and future directions. Arch Osteoporos. 2018;13:90.

2. Clark P, Denova-Gutierrez E, Zerbini C, Sanchez A, Messina O, Jaller JJ, et al. FRAX-based intervention and assessment thresholds in seven Latin American countries. Osteoporos Int. 2018;29:707-15.

3. Harvey N, Dennison E, Cooper C. Osteoporosis: impact on health and economics. Nat Rev Rheumatol. 2010;6:99-105.

4. Delmas PD, Marin F, Marcus R, Misurski DA, Mitlak BH. Beyond hip: importance of other nonspinal fractures. Am J Med. 2007;120:381-7.

5. Singer A, Exuzides A, Spangler L, O'Malley C, Colby C, Johnston K, et al. Burden of illness for osteoporotic fractures compared with other serious diseases among postmenopausal women in the United States. Mayo Clin Proc. 2015;90:53-62

6. Clark P, Cons-Molina F, Deleze M, Ragi S, Haddock L, Zanchetta JR, et al. The prevalence of radiographic vertebral fractures in Latin American countries: the Latin American vertebral osteoporosis study (LAVOS). Osteoporos Int. 2009;20:275-82

7. Cooper C, Campion G, Melton L Jr. Hip fractures in the elderly: a world-wide projection. Osteoporos Int. 1992;2:285-9.

8. Forsteo Summary of Product Characteristics. Indianapolis, IN: Eli Lilly and Company; 2013. Available at: https:/www.ema.europa.eu/en/documents/productinformation/forsteo-epar-product-information_en.pdf [Last accessed 30 Jan 2019].

9. Forteo prescribing information. Indianapolis, IN: Eli Lilly and Company; 2012. Available at: https://pi.lilly.com/us/forteo-pi.pdf [Last accessed 30 Jan 2019].

10. Chen CH, Elsalmawy AH, Ish-Shalom S, Lim SJ, Al-Ali NS, Cunha-Borges JL, et al. Study description and baseline characteristics of the population enrolled in a multinational, observational study of teriparatide in postmenopausal women with osteoporosis: the Asia and Latin America fracture observational study (ALAFOS). Curr Med Res Opin. 2019;35:1041-9.

11. The University of Sheffield. FRAX ${ }^{\circledR}$ Fracture Risk Assessment Tool. Available at: http://www.shef.ac.uk/FRAX [Last accessed 30 Jan 2019].

12. McCloskey E. FRAX ${ }^{\circledR}$ identifying people at high risk of fracture. International Osteoporosis Foundation; 2009. Available at: http://www.iofbonehealth.org/ sites/default/files/media/PDFs/FRAX_report_16.pdf [Last accessed 30 Jan 2019].

13. Salica D, Buceta Paley AM, Palacios S, Sánchez A, Ragi Eis S, Zeghbi Cochenski Borba V, et al. Iberoamerican consensus of osteoporosis SIBOMM 2009. Prevention, Diagnosis, and Treatment. International Osteoporosis Foundation: Osteoporosis; 2009. Available at: https://www.iofbonehealth.org/sites/default/ files/PDFs/National\%20Guidelines/SIBOMMConsensus-2009-english.pdf [Last accessed 30 Jan 2019].

14. Orjuela AM, Olarte OR, Plata PNR, Escobar FS, Choueka MC, González Reyes MA, et al. II Consenso Colombiano para el manejo de la osteoporosis posmenopáusica (Second Colombian consensus on the management of post-menopausal osteoporosis: 2017 update). Rev Colomb Reumatol. 2018; 25:184-210.

15. Schurman L, Galich AM, González C, González D, Messina OD, Sedlinsky C, et al. Guías Argentinas para el diagnóstico, la prevención y el tratamiento de la osteoporosis 2015 (Argentine guidelines for the diagnosis, prevention and treatment of osteoporosis, 2015). Medicina (B Aires). 2017;77:46-60.

16. Radominski SC, Bernardo W, Paula AP, Albergaria BH, Moreira C, Fernandes CE, et al. Brazilian guidelines for the diagnosis and treatment of postmenopausal osteoporosis. Rev Bras Reumatol Engl Ed. 2017;57(Suppl 2):452-66.

17. Ministério da Sáude Consultoria Jurídica/Advocacia Geral da União. Nota Técnica N 58/2012, Brasília, maio de 2012. Avaiable at: http:// portalarquivos2.saude.gov.br/images/pdf/2014/setembro/17/Teriparatida\%2 D\%2Datualiazada-em-15-10-2013-.pdf [Last accessed 27 Aug 2019].

18. Diagnóstico y tratamiento de osteoporosis en mujeres postmenopáusicas. Guía de Referencia Rápida: Guía de Práctica Clínica. México, CENETEC; 2018. Available at http://www.imss.gob.mx/sites/all/statics/guiasclinicas/673GRR.pdf [Last accessed 23 Aug 2019].

19. Fahrleitner-Pammer A, Langdahl BL, Marin F, Jakob F, Karras D, Barrett A, et al. Fracture rate and back pain during and after discontinuation of teriparatide: 36-month data from the European Forsteo observational study (EFOS). Osteoporos Int. 2011;22:2709-19.

20. Ljunggren O, Benhamou CL, Dekker J, Kapetanos G, Kocjan T, Langdahl BL, et al. Study description and baseline characteristics of the population enrolled in a multinational observational study of extended teriparatide use (ExFOS). Curr Med Res Opin. 2014;30:1607-16.

21. Napoli N, Langdahl BL, Ljunggren Ö, Lespessailles E, Kapetanos G, Kocjan T, et al. Effects of teriparatide in patients with osteoporosis in clinical practice: 42-month results during and after discontinuation of treatment from the European extended Forsteo ${ }^{\oplus}$ observational study (ExFOS). Calcif Tissue Int. 2018;103:359-71.

22. Rajzbaum G, Jakob F, Karras D, Ljunggren O, Lems WF, Langdahl BL, et al. Characterization of patients in the European Forsteo observational study (EFOS): postmenopausal women entering teriparatide treatment in a community setting. Curr Med Res Opin. 2008;24:377-84.

23. Silverman S, Miller P, Sebba A, Weitz M, Wan X, Alam J, et al. The direct assessment of nonvertebral fractures in community experience (DANCE) study: 2-year nonvertebral fragility fracture results. Osteoporos Int. 2013;24:2309-17.

24. Pinheiro MM, Ciconelli RM, Martini LA, Ferraz MB. Clinical risk factors for osteoporotic fractures in Brazilian women and men: the Brazilian osteoporosis study (BRAZOS). Osteoporos Int. 2009;20:399-408.

25. Cano-Gutiérrez C, Borda MG, Reyes-Ortiz C, Arciniegas AJ, Samper-Ternent R. Evaluación de factores asociados al estado funcional en ancianos de 60 años o más en Bogotá, Colombia (Assessment of factors associated with functional status in 60 years-old and older adults in Bogota, Colombia). Biomedica. 2017:37:57-65.

26. Zanchetta J, Campusano C, Muzzi B, Terront A, Cerdas S, Molina FC, et al. The Latin America regional audit - epidemiology, costs \& burden of osteoporosis in 2012. International Osteoporosis Foundation; 2012. Available at: https://www.iofbonehealth.org/sites/default/files/media/PDFs/Regional\%2 OAudits/2012-Latin_America_Audit_0_0.pdf [Last accessed 30 Jan 2019].

27. Johansson H, Clark P, Carlos F, Oden A, McCloskey EV, Kanis JA. Increasing age- and sex-specific rates of hip fracture in Mexico: a survey of the Mexican Institute of Social Security. Osteoporos Int. 2011;22:2359-64.

28. Morales-Torres J, Gutiérrez-Ureña S. Osteporosis Committee of panAmerican League of associations for rheumatology. The burden of osteoporosis in Latin America. Osteoporos Int. 2004;15:625-32.

\section{Publisher's Note}

Springer Nature remains neutral with regard to jurisdictional claims in published maps and institutional affiliations.
Ready to submit your research? Choose BMC and benefit from:

- fast, convenient online submission

- thorough peer review by experienced researchers in your field

- rapid publication on acceptance

- support for research data, including large and complex data types

- gold Open Access which fosters wider collaboration and increased citations

- maximum visibility for your research: over $100 \mathrm{M}$ website views per year

At $\mathrm{BMC}$, research is always in progress.

Learn more biomedcentral.com/submissions 